\title{
Thermal stability and performance trends of sustainable lignocellulosic olive / low density polyethylene biocomposites for better environmental green materials
}

\author{
Faris M. AL-Oqla ${ }^{a^{*}}$, M.H. Alaaeddin ${ }^{\mathrm{b}}$ and Yousuf A. El-Shekeil
}

${ }^{a}$ Department of Mechanical Engineering, Faculty of Engineering, The Hashemite University, Zarqa 13133, Jordan

${ }^{b}$ Faculty of Engineering, Universiti Putra Malaysia, Serdang, 43400 Seri Kembangan, Selangor, Malaysia

${ }^{c}$ Department of Mechanical Engineering, College of Engineering at Yanbu, Taibah University, Kingdome of Saudi Arabia

\begin{tabular}{l}
\hline A R T I C L E I N F O \\
\hline Article history: \\
Received 10 September 2020 \\
Accepted 5 May 2021 \\
Available online \\
9 May 2021 \\
\hline Keywords: \\
Biomaterials \\
Lignocellulosic fibers \\
Mechanical performance \\
Sustainability \\
Olive leaf \\
Green products
\end{tabular}
\begin{abstract}
A B S T R A C T
The current trend in deteriorating mechanical performance of green polymeric-based materials has made it essential for designers to establish more reliable and sustainable bio-products. Here, the mechanical performance of Jordanian lignocellulosic olive fibers in polymeric-based composites has been methodically investigated. The outcomes of different reinforcement conditions on the desired mechanical performance of the olive leaf's lignocellulosic fibers with low-density polyethylene (LDPE) composites have been examined, including the properties of tensile strength, tensile modulus, mechanical strain, impact strength, and the intensity per composite volume. This has been accomplished to determine the optimum reinforcement condition for the desired mechanical behavior as well as to establish the performance deterioration and enhancement trends of such bio-materials in a more consistent manner. The results signify that lignocellulosic olive fibers have exhibited various enhancements in terms of mechanical performance. Both the tensile strength and modulus of elasticity have been dramatically improved at $20 \mathrm{wt} . \%$ fiber content. This was the most desired reinforcement condition among all considered cases. The olive fibers also possess the capability of maintaining relatively high ductility and impact strength properties, making them suitable for various industrial applications where high ductility is necessary. Thermal stability analysis using TGA and DTG has been employed to obtain accurate results.
\end{abstract}

\section{Introduction}

Determining the most suitable constituent materials for green products has become key for the success of generating new eco-friendly products. The mechanical performance of green materials applied in bio-products and their technologies are of paramount importance for acquiring more reliable and sustainable designs(Faris M AL-Oqla, 2017; Faris M. AL-Oqla \& Salit, 2017b; Alaaeddin, Sapuan, Zuhri, Zainudin, \& AL-Oqla, 2019b). Hence, there is a growing need to develop and support the production of bio-products with low-cost biomaterials to extend their application in truly sustainable societies. However, numerous constraints limit the utilization of specific materials in particular industries (Faris M AL-Oqla, Almagableh, \& Omari, 2017; F.M. AL-Oqla \& Hayajneh, 2007; F. M. AL-Oqla \& S. Sapuan, 2014; Dweiri \& Al-Oqla, 2006; Liu et al., 2018; Luc Toupe, Trokourey, \& Rodrigue, 2014). Diverse performance parameters must be considered to guarantee the appropriateness of such materials (Faris M AL-Oqla, Hayajneh, \& Fares, 2019; Faris M AL-Oqla \& Sapuan, 2017; Aridi, Sapuan, Zainudin, \& AL-Oqla, 2017; Rashid, Leman, Jawaid, Ishak, \& Al-Oqla, 2017). Bio-composites have been increasingly considered as sustainable and eco-friendly alternatives to conventional composites due to several competitive characteristics; they are light weight, low in cost, possess significant specific properties, recyclable, and degradable (Faris M AL-Oqla \& El-Shekeil, 2019; Alaaeddin, Sapuan, Zuhri, Zainudin, \& AL-Oqla, 2019a; Alaaeddin, Sapuan, Zuhri, Zainudin, $\&$ M AL-Oqla, 2019b). Wide varieties of natural fibers are applied as reinforcements for different polymeric materials. They can be used as raw material sources for sustainable and renewable products. Although several researchers had examined the

* Corresponding author.

E-mail addresses: Fmaloqla@hu.edu.jo (F. M. AL-Oqla) 
capabilities of bio-composites as sustainable alternatives (Abdal-hay, Suardana, Jung, Choi, \& Lim, 2012; Alaaeddin, Sapuan, Zuhri, Zainudin, \& M AL-Oqla, 2019a; Alawar, Hamed, \& Al-Kaabi, 2009; Mir, Nafsin, Hasan, Hasan, \& Hassan, 2013; Pan \& Zhong, 2014; Sapuan, Pua, El-Shekeil, \& AL-Oqla, 2013), only a few had actually investigated how to evaluate and select the proper constituents of natural fiber composites. Promising steps have been recently achieved in this direction to help engineers evaluate and select particular sustainable applications (Faris M AL-Oqla \& Rababah, 2017; Faris M AL-Oqla, S. M. Sapuan, M. R. Ishak, \& A.A., 2015; Faris M. AL-Oqla \& Salit, 2017a). Some encouraging steps include categorizing the factors that affect the natural fiber composites in a simultaneously combined evaluation criteria to better assess the competencies of the natural fibers considered (Faris M AL-Oqla, Sapuan, Ishak, \& Aziz, 2014; Faris M AL-Oqla \& Sapuan, 2018; Faris M AL-Oqla, Sapuan, Ishak, \& Nuraini, 2016; Faris M AL-Oqla, Sapuan, Ishak, \& Nuraini, 2014; Faris M ALOqla, Sapuan, \& Jawaid, 2016).

The physical characteristics and the final mechanical performance of bio-materials are strongly reliant on the physical features of their distinct constituencies as well as the compatibility between them (Faris M. AL-Oqla \& Salit, 2017a; F. M. AL-Oqla \& S. M. Sapuan, 2014b; Deng, Hu, Deng, \& Mahadevan, 2014; Nurwaha, Han, \& Wang, 2013; Ojha, Raghavendra, \& Acharya, 2014; Sapuan et al., 2013; Yu \& Yu, 2010). Therefore, functional requirements (such as mechanical behavior, degradation, and thermal properties) commonly control the required features of products composed of bio-materials. Lignocellulosic fibers are considered to be the chief constituents of polymeric-based composites since they are independent elements in biomaterials (F. M. AL-Oqla \& S. M. Sapuan, 2014c). They possess their own intrinsic characteristics that cannot be considerably altered through the modifications or treatments of matrix types. Improper evaluation of lignocellulosic fiber capabilities in biomaterials can cause various types of environmental waste problems. Their desired functional characteristics will also be limited in several industrial applications(Al-Ghraibah, Al-Qudah, \& AL-Oqla, 2020; Faris M AL-Oqla, 2020a, 2020b; Faris M AL-Oqla \& Hayajneh, 2020; Faris M AL-Oqla \& Sapuan, 2020; Fares \& AL-Oqla, 2020; Faris, Faris, ALOqla, \& Dalalah, 2020; Gholampour \& Ozbakkaloglu, 2020). Only certain varieties of lignocellulosic fibers are commercially employed for biomaterials and bio-products. Other types are usually ignored or undervalued (Faris M AL-Oqla, 2017; Faris M AL-Oqla, Sapuan, \& Jawaid, 2016; F. M. AL-Oqla \& S. M. Sapuan, 2014a, 2014b; F. M. K. F. AL-OQLA, 2015; Aridi, Sapuan, Zainudin, \& AL-Oqla, 2016a, 2016b). Therefore, it is essential to explore new and different lignocellulosic fibers in polymeric-based materials to develop more desired attributes for future bio-products since they are relatively low in cost and good sources of renewable materials.

The olive tree (Olea europaea L.) is a Mediterranean tree that has been around for decades. It can be found in various regions worldwide. Around 900 million olive trees are cultivated across the world due to their beneficial oil and fruits, which can be considered as a main source of food in some populations (Alshammari et al., 2019). The leaf of the olive tree is composed of $11.28 \mathrm{wt} . \%$ cellulose, $14.73 \mathrm{wt} . \%$ hemicellulose, only $16.33 \mathrm{wt} . \%$ lignin, and $57.66 \mathrm{wt} . \%$ of other components (Alshammari et al., 2019). Table 1 displays the composition of the olive tree. The olive tree's fruit and stone residues as well as its oil have been researched in the bio-composite field (Faris M AL-Oqla, 2021; AL-Oqla, 2021; Essien, Kavaz, Ituen, \& Umoren, 2018; Harb, Abubshait, Etteyeb, Kamoun, \& Dhouib, 2020; Koutsomitopoulou, Bénézet, Bergeret, \& Papanicolaou, 2014; Mousa, Heinrich, \& Wagenknecht, 2010; Naghmouchi, Mutjé, \& Boufi, 2014). However, the lignocellulosic fibers of the olive tree leaves have not been appropriately utilized in polymeric-based composites, making them an environmental waste issue.

Table 1. Compositions of olive tree (Alshammari et al., 2019)

\begin{tabular}{llll}
\hline Chemical composition of olive tree (wt.\%) & leaf & stem & big branches \\
\hline Cellulose & 11.28 & 39.07 & 39.42 \\
Hemicellulose & 14.73 & 23.62 & 24.23 \\
Lignin & 16.33 & 13.26 & 14 \\
Other & 57.66 & 24.05 & 22.35 \\
\hline
\end{tabular}

Therefore, this work methodically investigates the mechanical performance of Jordanian lignocellulosic olive fibers in polymeric-based composites, particularly the low-density polyethylene polymer type. This will not only eliminate the annually accumulating agro-waste fibers, but also enhance the development of ecofriendly materials with desired characteristics for more realistic green products. Here, the consequences of different reinforcement conditions on the desired mechanical performance of olive leaf lignocellulosic fibers/low density polyethylene have been examined. This includes the properties of tensile strength, tensile modulus, mechanical strain, impact strength, and intensity per composite volume to acquire the optimal reinforcement condition for the preferred mechanical behavior. This will reveal the performance deterioration and enhancement trends of such bio-materials in a more consistent manner.

\section{Materials and Methods}

The considered polymer matrix is low density polyethylene (LDPE) provided by the SABIC company. Its density is 919 $\mathrm{Kg} / \mathrm{m}^{3}$, its tensile strength at break is $7 \mathrm{MPa}$, and its modulus of elasticity is $165 \mathrm{MPa}$. Lignocellulosic olive leaves were collected from Jordan. They were washed with distilled water and air-dried at room temperature. The leaves were then cut into small pieces and mixed with LDPE in a hot mixer machine with countered double screws. The mixtures were then pressed 
under heat for about 15 minutes to produce sheets with minimal thermal shrinkage. Various composite designs were performed with different fiber contents of $10 \mathrm{wt} . \%, 20 \mathrm{wt} . \%, 30 \mathrm{wt} . \%$, and $40 \mathrm{wt} . \%$. The produced sheets were then cut into specimens to perform the necessary tests. The standard tensile test technique was utilized to measure the mechanical properties of the prepared composites, including the tensile strength, the modulus of elasticity, and the mechanical strain. Instron 3365 machine was used to conduct the tensile tests. The testing was repeated five times according to the ASTM D638 standard. Fibers as well as sample of specimens in addition to the experimental setup demonstrating the unit load cell, data acquisition, actuator, hydraulic cross system and software controller are illustrated in Fig. 1. The average values were successfully acquired. The impact strength was measured with the Charpy method, according to ISO 179, using unnotched flatwise samples.

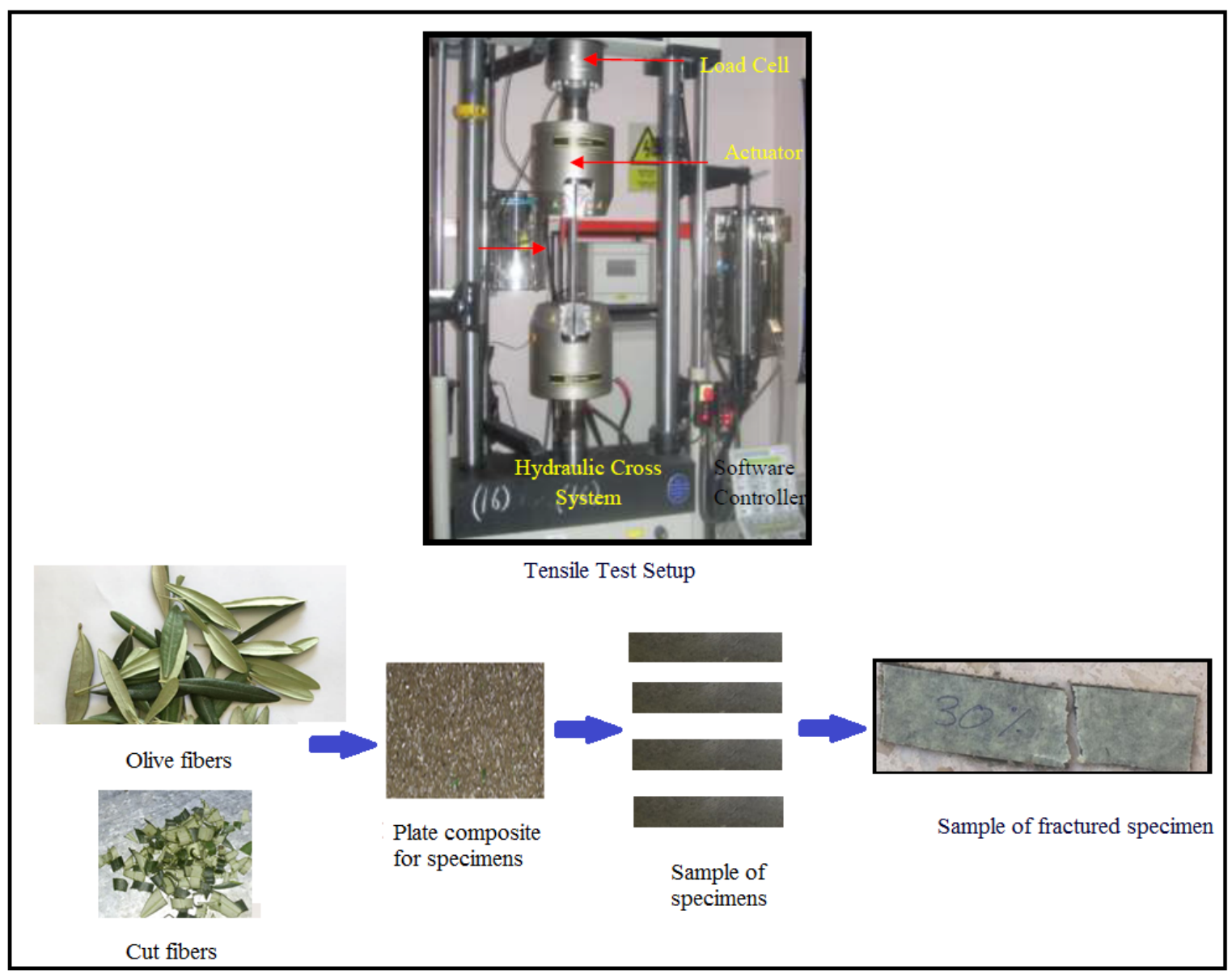

Fig. 1. Illustration of the experimental setup, fibers and composite specimens

The thermal stability of the olive leaf fibers was also examined using both thermogravimetric analysis (TGA) and derivative weight $(\% / \mathrm{min})$ (DTG). These tests are essential for monitoring any changes in the physical and chemical characteristics of the olive leaf fibers while increasing the temperature at a constant rate. This was in fact necessary to investigate the mass loss of the cellulosic fibers and their decomposition behavior. The instrument model NETZSCH TG 209F1 was utilized to perform the TGA experiments where thermal stability was evaluated at a heating rate of $10^{\circ} \mathrm{C} / \mathrm{min}$. The morphological characteristics of the prepared composites were investigated using a scanning electron microscope (SEM). This was implemented to demonstrate the surface of the fracture side of composites to support their performance assessment and the outcomes gained in this work.

\section{Results and Discussion}

One major achievement of this work is determining whether utilizing the available lignocellulosic olive waste fibers from Jordan for producing green bio-materials would be suitable. This is necessary to establish so as to effectively employ the abundant lignocellulosic agricultural waste resulting from Jordanian olives that have not been properly valorized in biomaterials. Determining the capabilities of the olive leaf in polymeric-based biomaterials can enhance their potential of becoming renewable ecofriendly alternatives and substitute other commonly used fibers worldwide. This will effectively solve an environmental waste problem. Various reinforcement conditions have been created and examined to determine their influence on the mechanical performance of LDPE/olive fibers. The stress strain diagrams of the prepared composites are 
displayed in Fig. 2. It can be seen that all composites are capable of enhancing the modulus of elasticity of the matrix since the Young's modulus of the fibers are better than that of the LDPE matrix. The fibers successfully enhanced the modulus of elasticity for all fiber loadings. The composites also had less ductility than the matrix, while some had better tensile strength compared to low density polyethylene. The optimum processing conditions of the prepared composites are extensively discussed for each considered mechanical property. Various fiber loadings have been employed to develop a better understanding of their behavior. This represents the possibilities of a sustainable design of bio-products in diverse industrial applications.

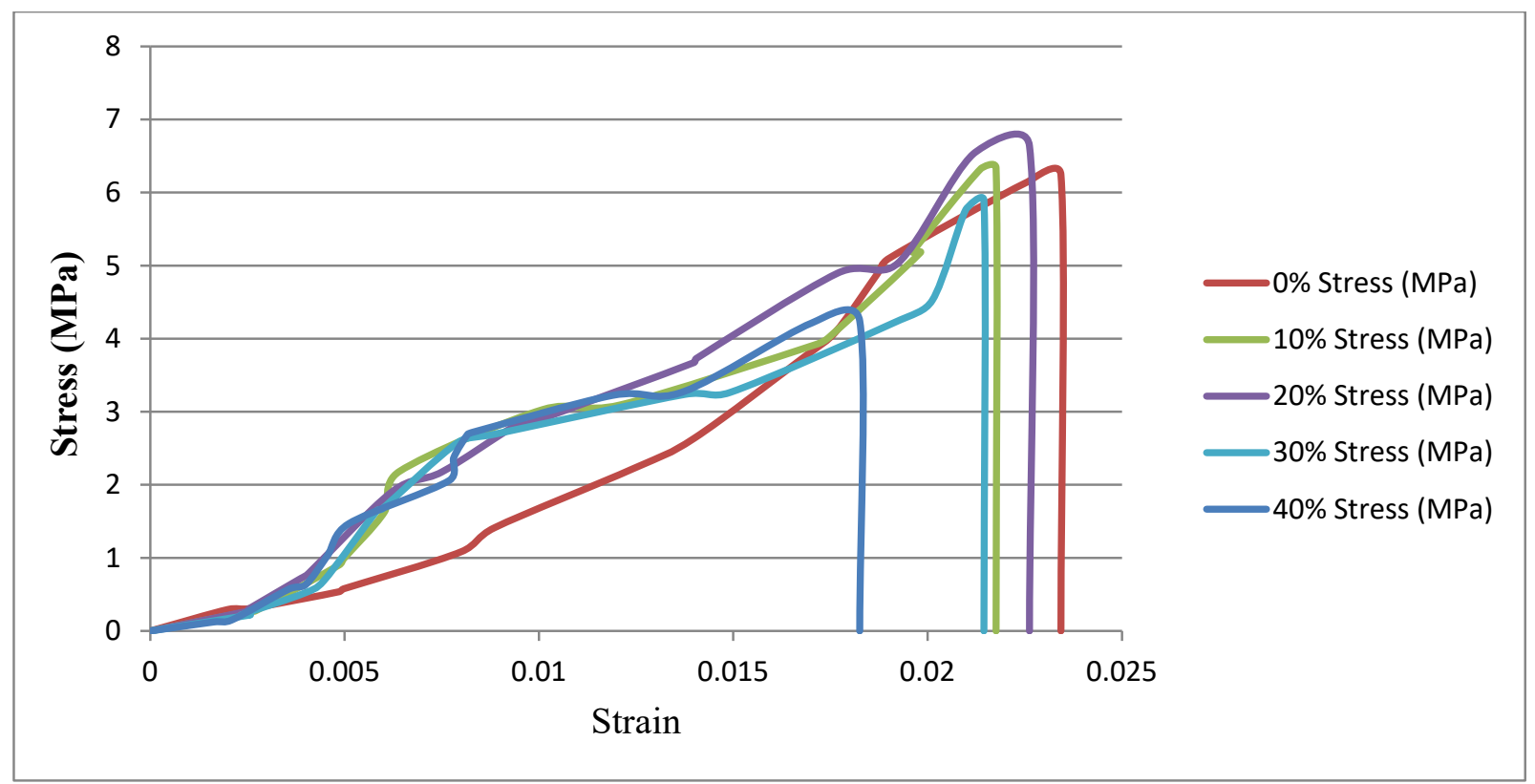

Fig. 2. Comparison of stress strain diagrams for various prepared composites

Thermogravimetric analysis (TGA) was employed to examine the thermal performance of olive leaf fibers in the matrix. This was according to the fibers' weight changes due to temperature, as shown in Fig. 3. Here, the physical characteristics were measured as a function of temperature increment while maintaining a constant heating rate. A thermal analyzer was utilized to conduct the TGA and measure the mass loss of the fibers. The thermal stability of the olive leaf fibers was examined via both TGA and derivative weight (\%/min) (DTG). It was clear that thermal degradation had occurred throughout several stages. The initial degradation began at around $90^{\circ} \mathrm{C}$ with less than $10 \%$ weight loss. This occurred as a result of moisture evaporation in the fibers. However, the second degradation stage was combined with substantial mass loss due to the degradation of hemicellulose, lignin, and wax. The last degradation was observed at around $370^{\circ} \mathrm{C}$ with about $16 \%$ weight loss. At $450^{\circ} \mathrm{C}$, degradation had occurred due to the elimination of $\alpha$-cellulose and lignin content from the fibers which continued to about $600^{\circ} \mathrm{C}$. This demonstrates the stability of the olive leaf fiber.

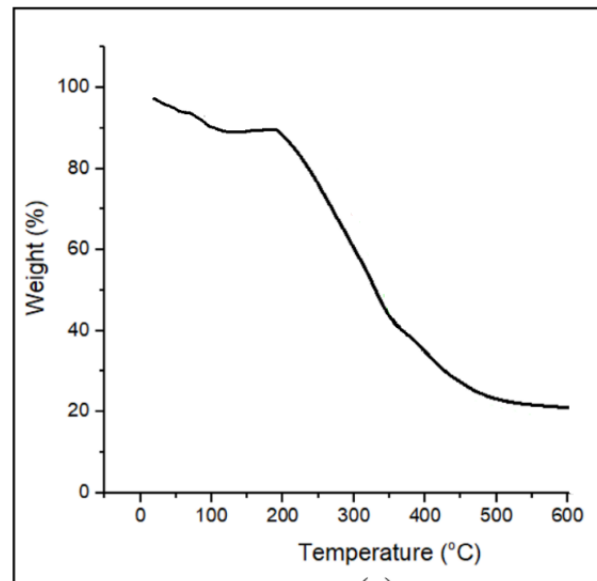

(a)

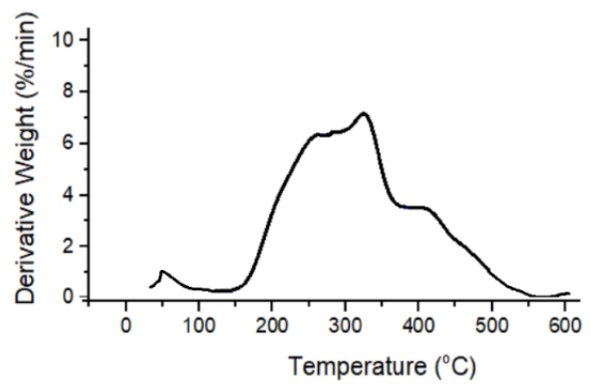

(b)

Fig. 3. Thermal stability analysis of the olive leaf using both (a) TGA and (b) DTG 
The tensile strength of the olive/LDPE composites with various fiber contents is illustrated in Fig. 4 . It can be seen that this mechanical property increased with fiber loading until $20 \mathrm{wt} . \%$, then later reduced as the fiber loading increased. It reached a maximum of $6.63 \mathrm{MPa}$ at $20 \mathrm{wt} . \%$ fiber loading and reduced to $4.24 \mathrm{MPa}$ at $40 \mathrm{wt} . \%$. The enhancement of the olive/LDPE's tensile strength was due to the effect of fiber adhesion to the matrix, leading to better stress transfer efficiency since their interfacial adhesion bond was favorable (Faris M AL-Oqla \& El-Shekeil, 2019; Alaaeddin, Sapuan, et al., 2019a; El-Shekeil, AL-Oqla, \& Sapuan, 2019). However, excess fiber loading is incapable of maintaining such an adhesion due to the poor wetting of all excess fibers in the matrix as compared to the ideal case.

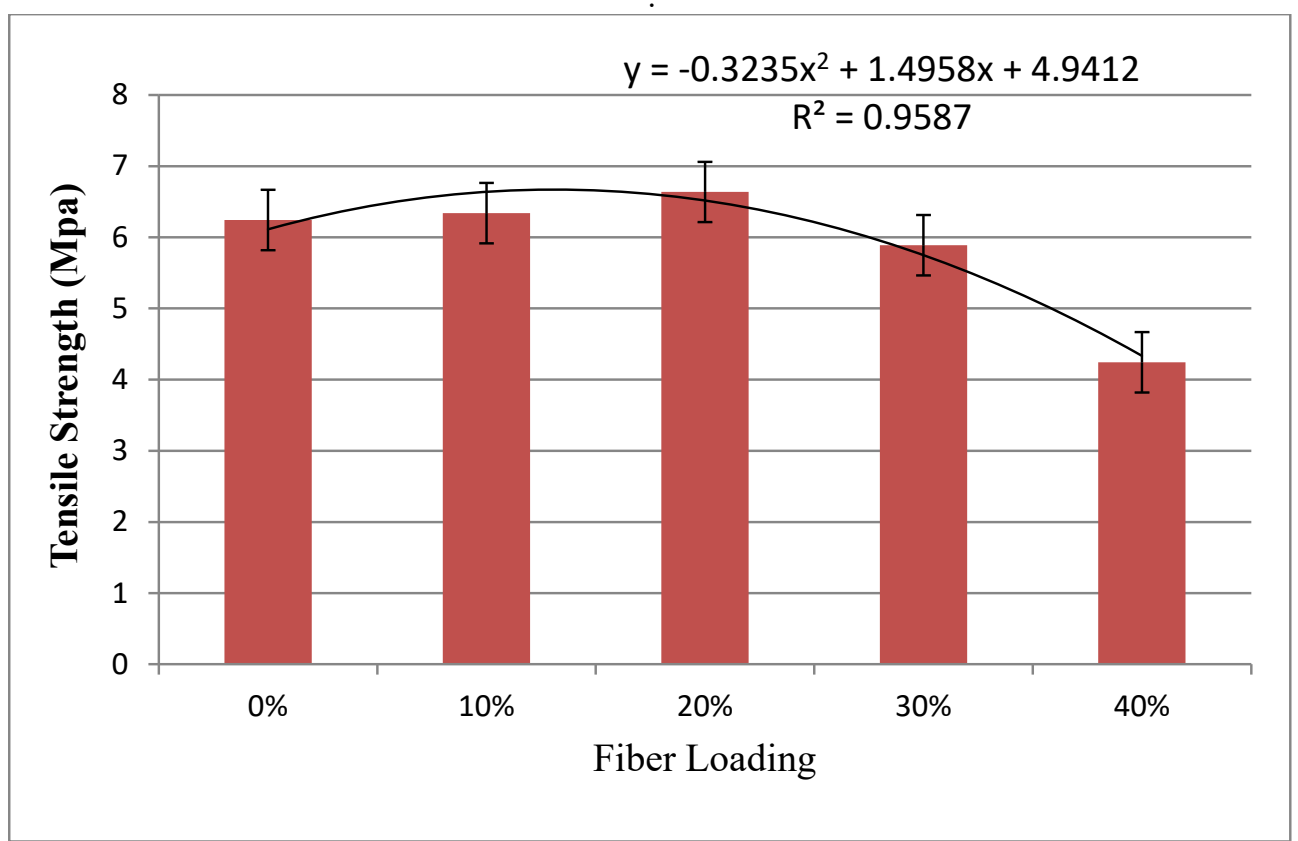

Fig. 4. Tensile strength of composite materials

The effect of fiber content on the tensile modulus of elasticity for the olive fibers/low density polyethylene composites is demonstrated in Fig. 5. It is apparent that this mechanical property had practically increased with fiber loading and reached the maximum at $20 \mathrm{wt} . \%$ fiber content. The optimal reinforcement condition is about $211 \%$ increment compared to the lowdensity polyethylene matrix. Nevertheless, the tensile modulus of elasticity had slightly reduced at $30 \mathrm{wt} . \%$ and $40 \mathrm{wt} . \%$ fiber contents due to the excess of lignocellulosic olive fibers. This led to lower adhesion between all fibers and matrix.

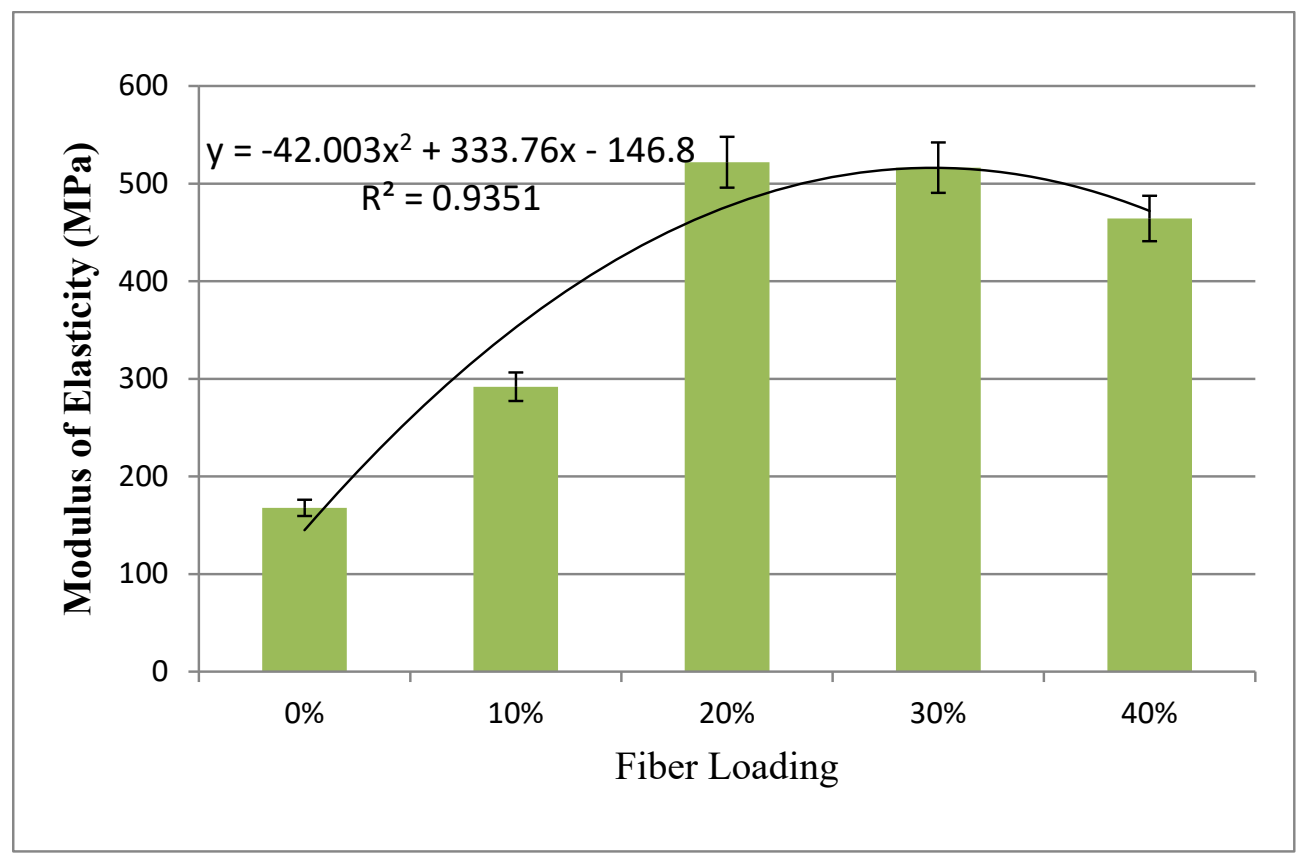

Fig. 5. Modulus of elasticity of considered composites with fiber contents 
The maximum strain at break was also investigated and displayed in Fig. 6. This property decreased for all composites in comparison to the matrix. This was in fact due to the effect of the olive fibers within the matrix, leading to an increase in brittleness since the strain of the lignocellulosic olive fibers was less than that of the low-density polyethylene matrix. The maximum strain was almost at $20 \mathrm{wt} \%$ fiber content, with about 0.0226. All composites were close together for this mechanical property and close to the matrix itself, indicating that utilizing lignocellulosic olive fibers in LDPE can enhance both the properties of tensile strength and modulus of elasticity while maintaining a relatively high ductility. This knowledge can be applied in specific industrial applications where high ductility is necessary.

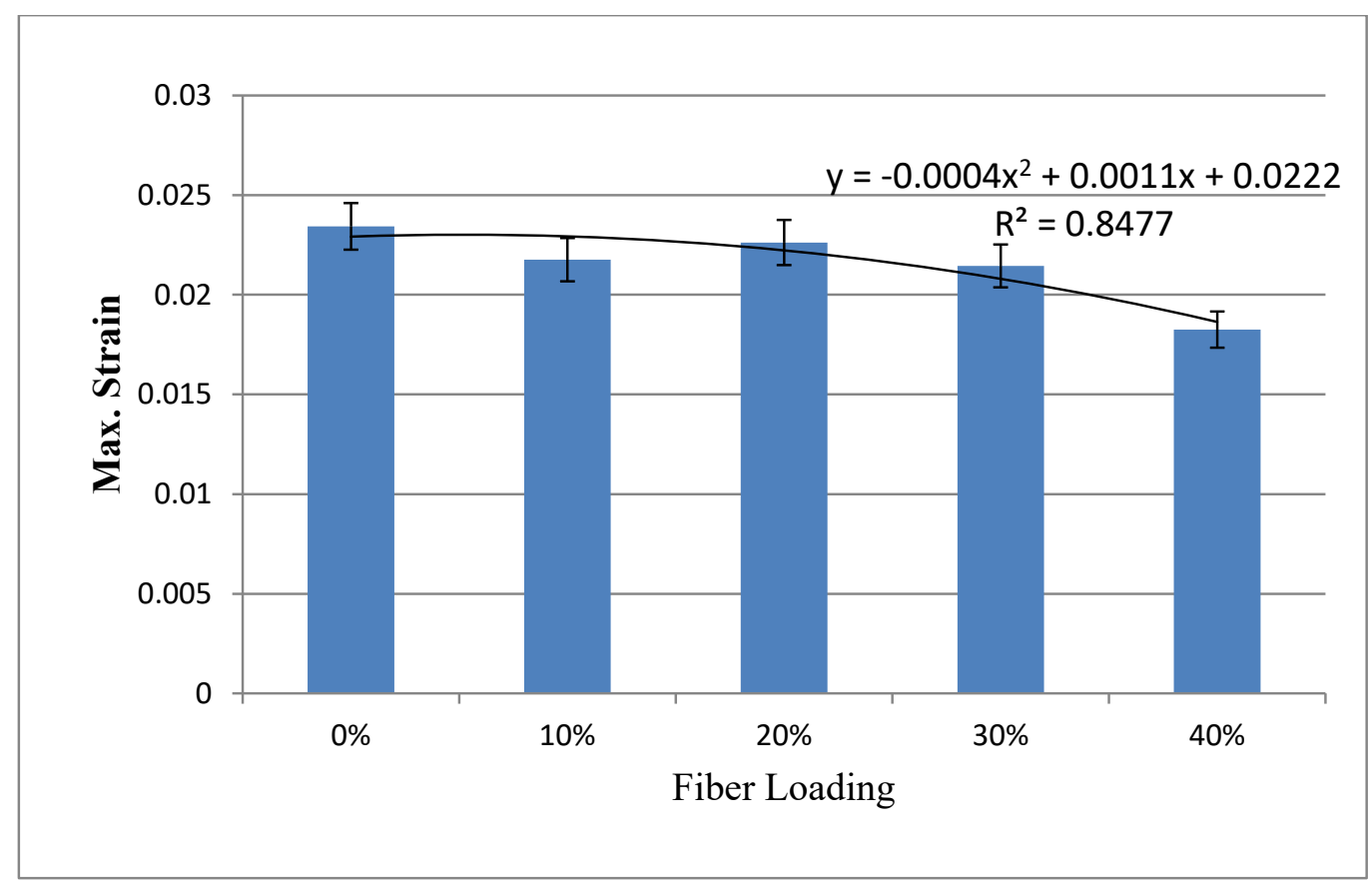

Fig. 6. Strain property of composites with various fiber contents

The impact strength of the considered composites was further analyzed to measure their toughness. This essential mechanical property is much desired in bio-composites since it can determine the required amount of energy to be absorbed by the composite per unit volume before rupturing in a sudden loaded environment. It is required that lignocellulosic composites have reasonable impact strength levels for various applications, such as automotive components for instance. The amounts of energy absorption of the considered bio-composites are illustrated in Fig. 7. It is clear that utilizing olive fibers in the LDPE polymer matrix significantly enhances energy absorption in comparison to the matrix itself. It reached an amount of $39 \mathrm{~J}$ at $30 \mathrm{wt} . \%$ fiber content compared to the polymer's energy which was absorbed by the polymer itself. The $130 \%$ enhancement in energy absorption indicates the potential of employing olive fibers for bio-composites in various sustainable bio-products.

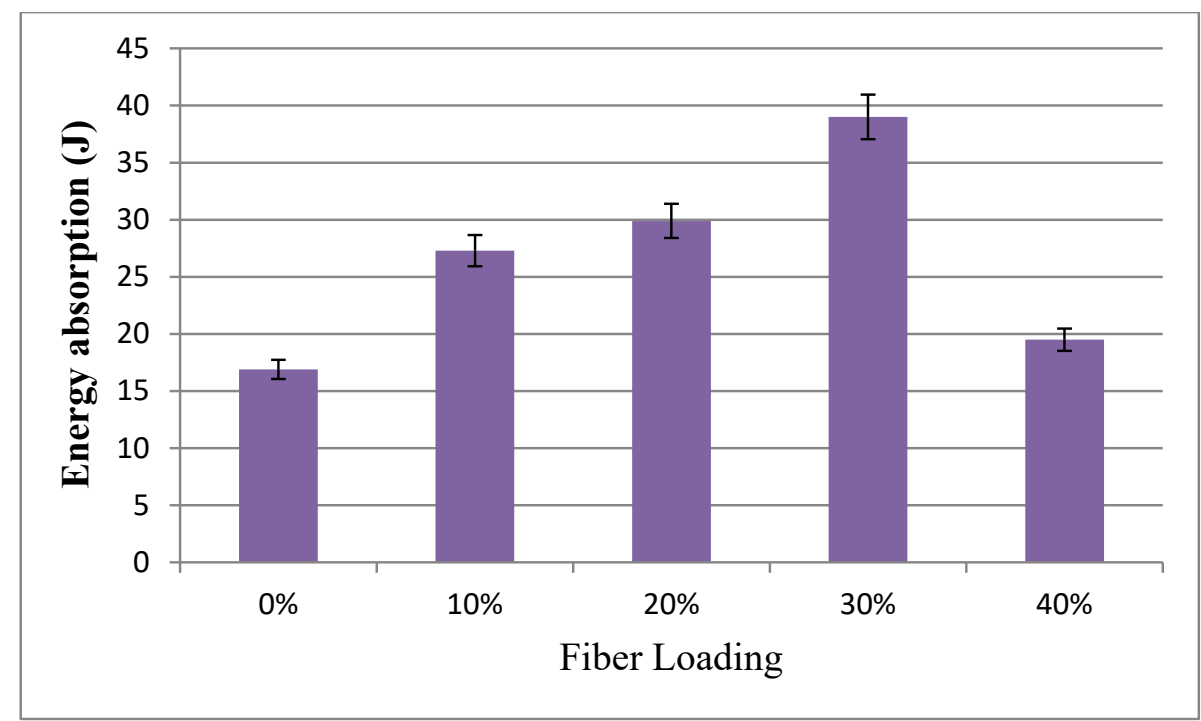

Fig. 7. Energy absorptions of composites with fiber contents 
The development of this desired mechanical property also signifies the proper adhesion between the olive fibers and the polymer since the main impact resistance in polymeric bio-composites usually originates from the matrix itself. The fibers, in most cases, reduce their impact abilities to enhance internal inclusions within the matrix if poor adhesion occurs (Faris M ALOqla, Sapuan, Ishak, et al., 2016); as in the case of $40 \mathrm{wt}$ \% fiber content. The energy absorption of the composites per volume $\left(\mathrm{MJ} / \mathrm{m}^{3}\right)$ is illustrated in Fig. 8. The outcomes indicate that $30 \mathrm{wt} . \%$ fiber content is the best when absorbing energy per volume for the olive/LDPE composites. The cases of $10 \mathrm{wt} . \%$ and $20 \mathrm{wt} . \%$ were relatively similar regarding this property. However, the worst absorbed amount of energy per unit volume was at $40 \mathrm{wt} . \%$ fiber content, indicating high inclusion distributions within the volume of the matrix and low adhesive forces between the fiber and matrix. The results are $4.5 \mathrm{MJ} / \mathrm{m}^{3}$ at $30 \mathrm{wt} . \%$, $3.3 \mathrm{MJ} / \mathrm{m}^{3}$ at $20 \mathrm{wt} . \%, 3.0 \mathrm{MJ} / \mathrm{m}^{3}$ at $10 \mathrm{wt} . \%$, but only $1.64 \mathrm{MJ} / \mathrm{m}^{3}$ at $40 \mathrm{wt} . \%$.

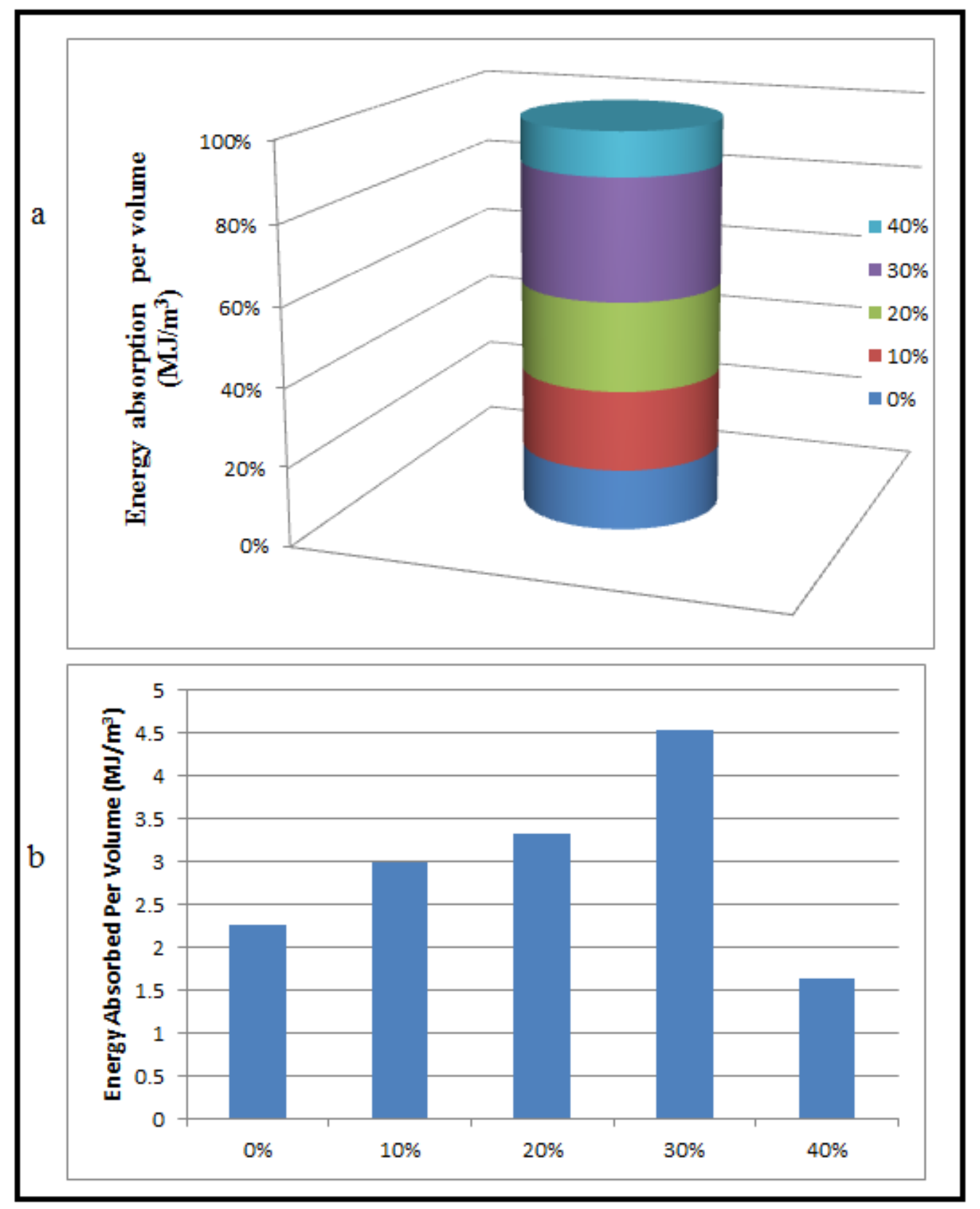

Fig. 8. Energy absorption of composites per volume: a) relative to fiber fraction; b) absolute with fiber loading

\section{Conclusions}

Green polymeric-based materials are essential for designers to create more reliable sustainable bio-products. This work successfully revealed various mechanical characteristics and performance trends of Jordanian lignocellulosic olive leaf fibers 
in low-density polyethylene-based composites. The impact of various fiber contents on the desired mechanical properties was effectively determined, including the enhancement of both tensile strength and tensile modulus properties. It can be concluded that olive leaf fibers can increase the impact resistance of the produced bio-composites without dismissing their ductility. Since bio-composites generally suffer from their impact resistance properties, this type can be utilized in various mechanical applications. This would encourage and provide more sustainable design opportunities for Jordan's low cost agro-waste fibers. The outcomes of this work provide accurate information for establishing a more robust database regarding green bio-product performance trends. This would not only promote the implementation of low-cost and renewable bio-composites in various industries, but also contribute determining the most ideal reinforcement conditions for a more practical sustainable industry.

\section{References}

Abdal-hay, A., Suardana, N. P. G., Jung, D. Y., Choi, K.-S., \& Lim, J. K. (2012). Effect of diameters and alkali treatment on the tensile properties of date palm fiber reinforced epoxy composites. International Journal of Precision Engineering and Manufacturing, 13(7), 1199-1206.

Al-Ghraibah, A. M., Al-Qudah, M., \& AL-Oqla, F. M. (2020). Medical Implementations of Biopolymers Advanced Processing, Properties, and Applications of Starch and Other Bio-Based Polymers (pp. 157-171): Elsevier.

AL-Oqla, F. M. (2017). Investigating the mechanical performance deterioration of Mediterranean cellulosic cypress and pine/polyethylene composites. Cellulose, 24(6), 2523-2530.

AL-Oqla, F. M. (2020a). Evaluation and Comparison of Date Palm Fibers with Other Common Natural Fibers Date Palm Fiber Composites (pp. 267-286): Springer.

AL-Oqla, F. M. (2020b). Flexural Characteristics and Impact Rupture Stress Investigations of Sustainable Green Olive Leaves Bio-composite Materials. Journal of Polymers and the Environment, 1-8.

AL-Oqla, F. M. (2021). Performance trends and deteriorations of lignocellulosic grape fiber/polyethylene biocomposites under harsh environment for enhanced sustainable bio-materials. Cellulose, 1-11.

AL-Oqla, F. M., Almagableh, A., \& Omari, M. A. (2017). Design and Fabrication of Green Biocomposites Green Biocomposites (pp. 45-67). Cham, Switzerland: Springer.

AL-Oqla, F. M., \& El-Shekeil, Y. (2019). Investigating and predicting the performance deteriorations and trends of polyurethane bio-composites for more realistic sustainable design possibilities. Journal of Cleaner Production, 222, 865870.

AL-Oqla, F. M., \& Hayajneh, M. T. (2007). A design decision-making support model for selecting suitable product color to increase probability. Paper presented at the Design Challenge Conference: Managing Creativity, Innovation, and Entrepreneurship.

AL-Oqla, F. M., \& Hayajneh, M. T. (2020). A hierarchy weighting preferences model to optimise green composite characteristics for better sustainable bio-products. International Journal of Sustainable Engineering, 1-6, DOI: 10.1080/19397038.2020.1822951.

AL-Oqla, F. M., Hayajneh, M. T., \& Fares, O. (2019). Investigating the mechanical thermal and polymer interfacial characteristics of Jordanian lignocellulosic fibers to demonstrate their capabilities for sustainable green materials. Journal of Cleaner Production, 241, 118256.

AL-Oqla, F. M., \& Rababah, M. (2017). Challenges in design of nanocellulose and its composites for different applications Cellulose-Reinforced Nanofibre Composites (pp. 113-127): Elsevier.

AL-Oqla, F. M., S. M. Sapuan, M. R. Ishak, \& A.A., N. (2015, March, 3, 2015). Selecting Natural Fibers for Industrial Applications. Paper presented at the Postgraduate Symposium on Biocomposite Technology Serdang, Malaysia.

AL-Oqla, F. M., \& Salit, M. S. (2017a). Material selection of natural fiber composites using the analytical hierarchy process Materials Selection for Natural Fiber Composites (Vol. 1, pp. 169-234). Cambridge, USA: Woodhead Publishing, Elsevier

AL-Oqla, F. M., \& Salit, M. S. (2017b). Materials Selection for Natural Fiber Composites (Vol. 1). Cambridge, USA: Woodhead Publishing, Elsevier.

AL-Oqla, F. M., Sapuan, M. S., Ishak, M. R., \& Aziz, N. A. (2014). Combined multi-criteria evaluation stage technique as an agro waste evaluation indicator for polymeric composites: date palm fibers as a case study. BioResources, 9(3), 46084621.

AL-Oqla, F. M., \& Sapuan, S. (2014). Natural fiber reinforced polymer composites in industrial applications: feasibility of date palm fibers for sustainable automotive industry. Journal of Cleaner Production, 66, 347-354.

AL-Oqla, F. M., \& Sapuan, S. (2017). Investigating the Inherent Characteristic/Performance Deterioration Interactions of Natural Fibers in Bio-Composites for Better Utilization of Resources. Journal of Polymers and the Environment, 1-7.

AL-Oqla, F. M., \& Sapuan, S. (2018). Investigating the inherent characteristic/performance deterioration interactions of natural fibers in bio-composites for better utilization of resources. Journal of Polymers and the Environment, 26(3), 12901296.

AL-Oqla, F. M., \& Sapuan, S. (2020). Advanced Processing, Properties, and Applications of Starch and Other Bio-Based Polymers. Cambridge, USA: Elsevier.

AL-Oqla, F. M., Sapuan, S., Ishak, M. R., \& Nuraini, A. (2016). A decision-making model for selecting the most appropriate natural fiber-Polypropylene-based composites for automotive applications. Journal of Composite Materials, 50(4), 543556. 
AL-Oqla, F. M., Sapuan, S., Ishak, M. R., \& Nuraini, A. A. (2014). A novel evaluation tool for enhancing the selection of natural fibers for polymeric composites based on fiber moisture content criterion. BioResources, 10(1), 299-312.

AL-Oqla, F. M., Sapuan, S., \& Jawaid, M. (2016). Integrated Mechanical-Economic-Environmental Quality of Performance for Natural Fibers for Polymeric-Based Composite Materials. Journal of Natural Fibers, 13(6), 651-659.

AL-Oqla, F. M., \& Sapuan, S. M. (2014a). Date Palm Fibers and Natural Composites. Paper presented at the Postgraduate Symposium on Composites Science and Technology 2014 \& 4th Postgraduate Seminar on Natural Fibre Composites 2014, 28/01/2014, Putrajaya, Selangor, Malaysia.

AL-Oqla, F. M., \& Sapuan, S. M. (2014b). Enhancement selecting proper natural fiber composites for industrial applications. Paper presented at the Postgraduate Symposium on Composites Science and Technology 2014 \& 4th Postgraduate Seminar on Natural Fibre Composites 2014, 28/01/2014, Putrajaya, Selangor, Malaysia.

AL-Oqla, F. M., \& Sapuan, S. M. (2014c). Natural fiber reinforced polymer composites in industrial applications: feasibility of date palm fibers for sustainable automotive industry. Journal of Cleaner Production, 66, 347-354.

AL-OQLA, F. M. K. F. (2015). Enhancement of evaluation methodologies for natural fiber composites material selection system. UPM, Malaysia.

AL-Oqla, F. M. (2021). Introduction to Biobased Composites. Biobased Composites: Processing, Characterization, Properties, and Applications, 1-14.

Alaaeddin, M., Sapuan, S., Zuhri, M., Zainudin, E., \& AL-Oqla, F. M. (2019a). Physical and mechanical properties of polyvinylidene fluoride-Short sugar palm fiber nanocomposites. Journal of Cleaner Production, 235, 473-482.

Alaaeddin, M., Sapuan, S., Zuhri, M., Zainudin, E., \& AL-Oqla, F. M. (2019b). Polymer matrix materials selection for short sugar palm composites using integrated multi criteria evaluation method. Composites Part B: Engineering, 107342.

Alaaeddin, M., Sapuan, S., Zuhri, M., Zainudin, E., \& M AL-Oqla, F. (2019a). Development of Photovoltaic Module with Fabricated and Evaluated Novel Backsheet-Based Biocomposite Materials. Materials, 12(18), 3007.

Alaaeddin, M., Sapuan, S., Zuhri, M., Zainudin, E., \& M AL-Oqla, F. (2019b). Lightweight and Durable PVDF-SSPF Composites for Photovoltaics Backsheet Applications: Thermal, Optical and Technical Properties. Materials, 12(13), 2104.

Alawar, A., Hamed, A. M., \& Al-Kaabi, K. (2009). Characterization of treated date palm tree fiber as composite reinforcement. Composites Part B: Engineering, 40(7), 601-606.

Alshammari, B. A., Alotaibi, M. D., Alothman, O. Y., Sanjay, M., Kian, L. K., Almutairi, Z., et al. (2019). A new study on characterization and properties of natural fibers obtained from olive tree (Olea europaea L.) residues. Journal of Polymers and the Environment, 27(11), 2334-2340.

Aridi, N., Sapuan, S., Zainudin, E., \& AL-Oqla, F. M. (2016a). Investigating morphological and performance deterioration of injection-molded rice husk-polypropylene composites due to various liquid uptakes. International Journal of Polymer Analysis and Characterization, 21(8), 675-685.

Aridi, N., Sapuan, S., Zainudin, E., \& AL-Oqla, F. M. (2016b). Mechanical and morphological properties of injection-molded rice husk polypropylene composites. International Journal of Polymer Analysis and Characterization, 21(4), $305-313$.

Aridi, N., Sapuan, S., Zainudin, E., \& AL-Oqla, F. M. (2017). A Review of Rice Husk Bio-Based Composites. Current Organic Synthesis, 14(2), 263-271.

Deng, X., Hu, Y., Deng, Y., \& Mahadevan, S. (2014). Supplier selection using AHP methodology extended by D numbers. Expert Systems with Applications, 41(1), 156-167.

Dweiri, F., \& Al-Oqla, F. M. (2006). Material selection using analytical hierarchy process. International journal of computer applications in technology, 26(4), 182-189.

El-Shekeil, Y., AL-Oqla, F., \& Sapuan, S. (2019). Performance tendency and morphological investigations of lignocellulosic tea/polyurethane bio-composite materials. Polymer Bulletin, 1-14.

Essien, E. A., Kavaz, D., Ituen, E. B., \& Umoren, S. A. (2018). Synthesis, characterization and anticorrosion property of olive leaves extract-titanium nanoparticles composite. Journal of adhesion science and Technology, 32(16), 1773-1794.

Fares, O. O., \& AL-Oqla, F. M. (2020). Modern Electrical Applications of Biopolymers Advanced Processing, Properties, and Applications of Starch and Other Bio-Based Polymers (pp. 173-184): Elsevier.

Faris, R., Faris, H., AL-Oqla, F. M., \& Dalalah, D. (2020). Evolving Genetic Programming Models for Predicting Quantities of Adhesive Wear in Low and Medium Carbon Steel Evolutionary Machine Learning Techniques (pp. 113-127): Springer.

Gholampour, A., \& Ozbakkaloglu, T. (2020). A review of natural fiber composites: Properties, modification and processing techniques, characterization, applications. Journal of Materials Science, 55(3), 829-892.

Harb, M. B., Abubshait, S., Etteyeb, N., Kamoun, M., \& Dhouib, A. (2020). Olive leaf extract as a green corrosion inhibitor of reinforced concrete contaminated with seawater. Arabian Journal of Chemistry, 13(3), 4846-4856.

Koutsomitopoulou, A., Bénézet, J., Bergeret, A., \& Papanicolaou, G. (2014). Preparation and characterization of olive pit powder as a filler to PLA-matrix bio-composites. Powder technology, 255, 10-16.

Liu, L., Liang, H., Zhang, J., Zhang, P., Xu, Q., Lu, Q., et al. (2018). Poly (vinyl alcohol)/Chitosan composites: Physically transient materials for sustainable and transient bioelectronics. Journal of Cleaner Production.

Luc Toupe, J., Trokourey, A., \& Rodrigue, D. (2014). Simultaneous optimization of the mechanical properties of postconsumer natural fiber/plastic composites: Phase compatibilization and quality/cost ratio. Polymer composites, 35(4), 730-746.

Mir, S. S., Nafsin, N., Hasan, M., Hasan, N., \& Hassan, A. (2013). Improvement of physico-mechanical properties of coirpolypropylene biocomposites by fiber chemical treatment. Materials \& Design, 52, 251-257. 
Mousa, A., Heinrich, G., \& Wagenknecht, U. (2010). Thermoplastic composites based on renewable natural resources: Unplasticized PVC/olive husk. International Journal of Polymeric Materials, 59(11), 843-853.

Naghmouchi, I., Mutjé, P., \& Boufi, S. (2014). Polyvinyl chloride composites filled with olive stone flour: mechanical, thermal, and water absorption properties. Journal of Applied Polymer Science, 131(22).

Nurwaha, D., Han, W., \& Wang, X. (2013). Effects of processing parameters on electrospun fiber morphology. Journal of the Textile Institute, 104(4), 419-425.

Ojha, S., Raghavendra, G., \& Acharya, S. (2014). A comparative investigation of bio waste filler (wood apple-coconut) reinforced polymer composites. Polymer composites, 35(1), 180-185.

Pan, Y., \& Zhong, Z. (2014). Modeling of the mechanical degradation induced by moisture absorption in short natural fiber reinforced composites. Composites Science and Technology.

Rashid, B., Leman, Z., Jawaid, M., Ishak, M. R., \& Al-Oqla, F. M. (2017). Eco-Friendly Composites for Brake Pads From Agro Waste: A Review in Reference Module in Materials Science and Materials Engineering: Elsevier.

Sapuan, S. M., Pua, F.-1., El-Shekeil, Y. A., \& AL-Oqla, F. M. (2013). Mechanical properties of soil buried kenaf fibre reinforced thermoplastic polyurethane composites. Materials \& Design, 50, 467-470.

$\mathrm{Yu}, \mathrm{H} .$, \& Yu, C. (2010). Influence of various retting methods on properties of kenaf fiber. Journal of the Textile Institute, 101(5), 452-456.

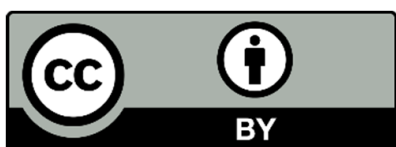

(C) 2021 by the authors; licensee Growing Science, Canada. This is an open access article distributed under the terms and conditions of the Creative Commons Attribution (CC-BY) license (http://creativecommons.org/licenses/by/4.0/). 